\title{
Doppler ultrasonography of canine maternal and fetal arteries during normal gestation
}

\author{
C. Poulsen Nautrup \\ Centre of Anatomy, Medical School of Hannover, D-30623 Hannover, Germany
}

\begin{abstract}
Two-dimensional ultrasonography was used in combination with colour-flow imaging and pulsed wave Doppler ultrasonography to study the maternal circulation and the development of fetal vascularization in six Beagles during normal gestation. For the first time, the development of the circulation was demonstrated in the bitch and her fetuses intra vitam. The bloodstream was examined in small uteroplacental arteries, the umbilical artery, the fetal aorta and the common carotid artery. The duration of the study was from week 3 after insemination until birth. Relatively large vessels were detected by cross-sectional ultrasonography, and small vessels were detected by colour-flow imaging. In pulsed wave Doppler ultrasonography, the blood flow was measured and described using the parameters of systolic peak velocity, diastolic peak velocity, end-diastolic velocity, pulsatility index, resistance index, A:B ratio (systolic peak velocity:end-diastolic velocity) and S:D parameter (systolic peak velocity:diastolic peak velocity). The development of the measured parameters is typical and similiar to that in humans. The systolic peak velocity of the canine maternal uteroplacental arteries shows important differences in comparison with humans. The pulsatility index, resistance index and A:B ratio decrease in nearly all vessels. Only the fetal common carotid artery has constant pulsatility and resistance indices during gestation. For the first time, the quality and quantity of the normal blood flow have been monitored during the whole of gestation. A normal circulation is fundamental for supplying the fetus adequately with oxygen and nutrients and thus for physiological development. These uitrasonographic results are the basis for further clinical studies.
\end{abstract}

\section{Introduction}

Conventional two-dimensional ultrasonography is used routinely to reveal and check canine pregnancy (Bondestam et al., 1983, 1984; Barr, 1988; England and Allen, 1990; England et al., 1990). Different parameters, such as gestation sac diameter, crown-rump length, fetal head diameter and fetal body diameter, show embryonic and fetal development, serve to estimate fetal age and can reveal growth retardation (England $e t$ al., 1990; Yeager et al., 1992). Nevertheless, the reasons for developmental alterations cannot be found in many cases. Moreover, a prognosis about further gestation is not possible using cross-sectional ultrasonography (England, 1993).

A better evaluation of the course of pregnancy can be achieved by monitoring the fetal supply with nutrients and oxygen, of which the maternal uteroplacental and fetal vascularization are indicators. A simple, non-invasive technique to show maternal and fetal circulation would be extremely valuable.

In human medicine, Doppler ultrasonography has been applied since 1977 (Fitzgerald and Drumm, 1977) and is now a standard method (Gonser and Vetter, 1995; Gonser, 1996). In the 1970 s and 1980 s, continuous wave (CW) Doppler ultra-

Received 28 April 1997 sonography was used. Today, pulsed wave (PW) Doppler ultrasonography, sometimes combined with colour-flow imaging, is used to describe physiological and pathological maternal and fetal vascularization during human pregnancy. The CW and PW Doppler ultrasonographic results are comparable (Bruner et al. 1994). These techniques have been used to diagnose and treat fetal outcome and distress (Alfirevic and Neilson, 1995; Molendijk et al., 1995).

Doppler ultrasonographic studies similar to those used in human obstetrics have been applied to pregnant sheep, an accepted animal model for human pregnancy (Irion and Clark, 1990; Van Huisseling et al., 1991; Arabeille et al., 1994; Sonesson et al., 1994).

The recorded blood flow pattern from CW or PW Doppler ultrasonography shows the frequency of Doppler shift or the blood flow velocity, which depends on the frequencies of the transmitted and reflected sound, the velocity of the moving target, the speed of sound in soft tissue and the angle between blood flow and ultrasound beam. In addition, the position of the Doppler gate within the vessel affects the amount of Doppler shift or blood flow velocity. The blood flow velocity is highest in the centre of the vessel. Because of the described sources of error and the low validity in diagnosing pregnancy aberrations, the absolute velocities are of little importance in human obstetrics (Meyberg and Sohn, 1995). 
Table 1. Measured blood flow velocities and calculated parameters used in this study to qualify and quantify canine maternal and fetal blood flow

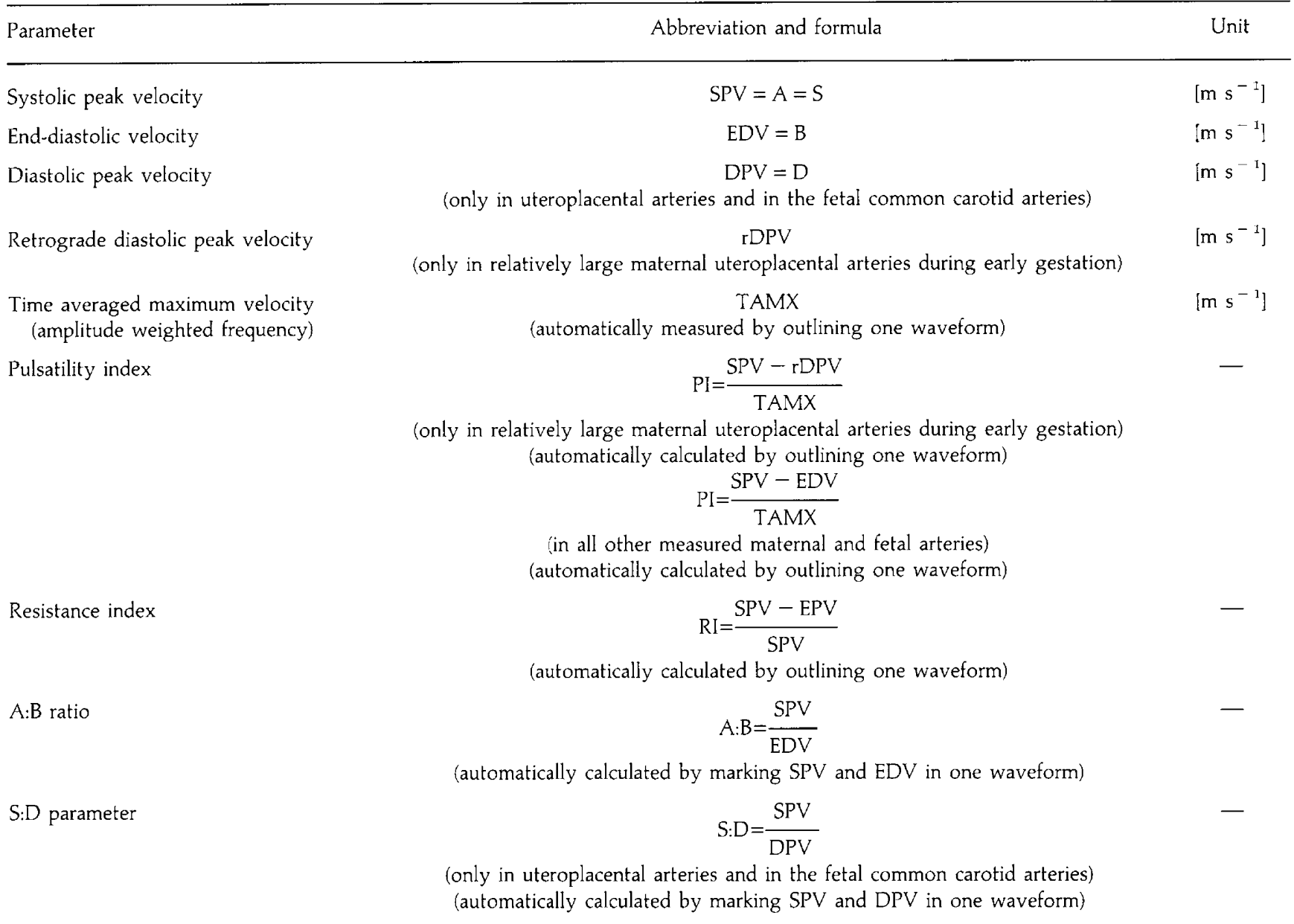

The waveforms recorded by conventional $\mathrm{CW}$ or $\mathrm{PW}$ Doppler uitrasonography show different patterns, dependent both on the proximal circulation (cardiac cycles, cardiac output, aortic wall elasticity and possible stenoses) and on the distal receiving bed (Evans et al., 1980). The velocity waveforms represent two different forms of arterial blood flow. Arteries show a low resistance flow if the following arterioles have a slight tonus. The systolic velocity increases relatively slowly to the systolic peak velocity (relatively flat waveform); the diastolic velocity decreases little and the end-diastolic velocity is relatively high. Well known canine arteries with low resistance flow are renal arteries. The renal blood flow has been described in healthy dogs as well as in dogs with artificial urinary tract obstruction and different renal diseases (Nyland et al., 1993; Morrow et al., 1996). Arteries show a high resistance flow if the following arterioles have a high tonus. The systolic velocity increases and decreases quickly (steep waveform). During early diastole, the blood flow is retrograde or stops, and the mid- and end-diastolic forward flow is low or absent. Typical arteries with high resistance flow are the canine femoral arteries at rest (Engelke and Gassner, 1996).

The objective evaluation of the waveforms is carried out by calculating velocity indices, which describe the relationship between the systolic and diastolic bloodstreams. The advantage of the indices is that there can be no mistakes in measurement, as there can be in calculating absolute velocities. Some velocity indices, commonly used in human obstetrics, are the resistance index (Pourcelot, 1974; sometimes named the resistive index), the pulsatility index (peak to peak measurement; Gosling and King, 1974) and the A:B ratio (systolic peak velocity:end-diastolic velocity; Stuart et al., 1980).

The aim of the present study was to show the physiological development of maternal uteroplacental and fetal arterial circulation in Beagles during normal gestation, using colour-flow imaging and PW Doppler ultrasonography. For the first time, the development of canine vascularization was monitored intra vitam during normal gestation. Therefore, the results are the basis for further clinical use of this method. The measured absolute velocities are correlated with the calculated indices, to find the most favourable parameter in each case.

\section{Materials and Methods}

During normal pregnancy, six healthy Beagle bitches of the Institute of Reproductive Medicine of the Veterinary School of 
(a)

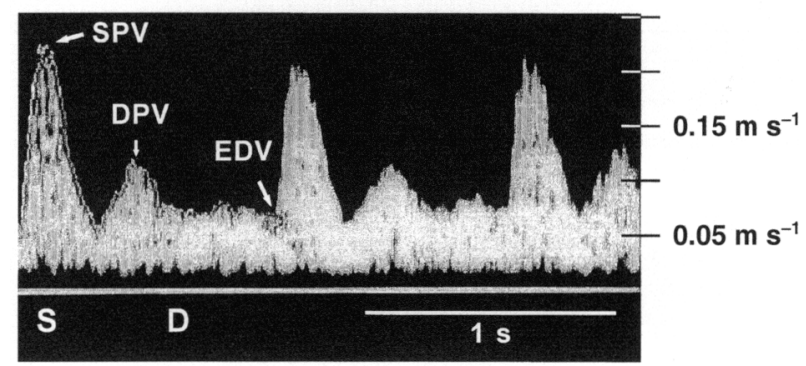

(b)

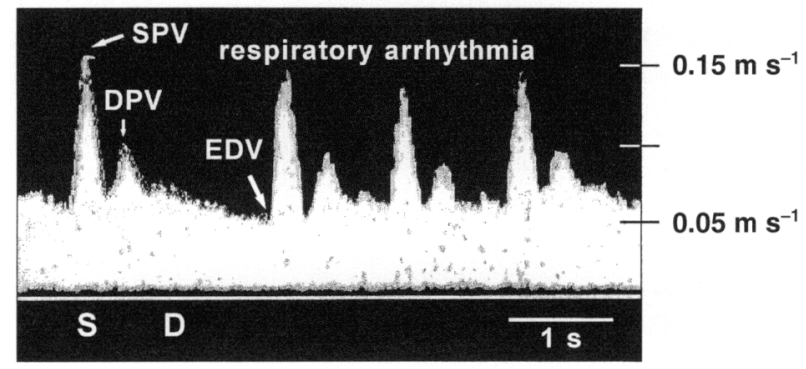

(c)

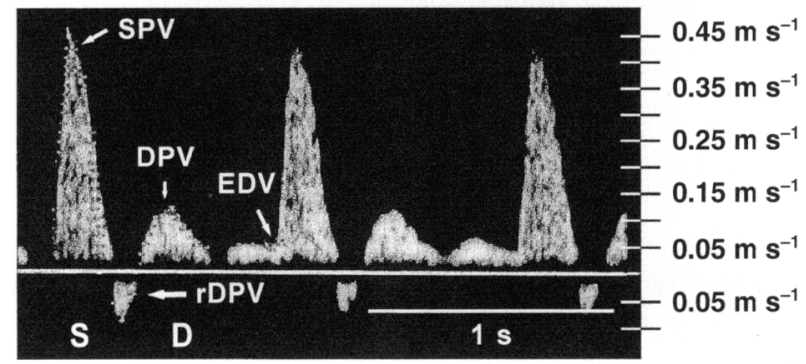

Fig. 1. Waveforms of two canine small maternal uteroplacental arteries $(a, b)$ and one larger maternal uteroplacental artery $(c)$ in week 3 after insemination. SPV, systolic peak velocity; DPV, diastolic peak velocity; EDV, end-diastolic velocity; rDPV, retrograde diastolic peak velocity; $S$, systole; $\mathrm{D}$, diastole.

Hannover were examined. The bitches were $4-8$ years old and weighed $11-16 \mathrm{~kg}$. Each had had at least two normal pregnancies.

The date of ovulation was determined by vaginoscopy, vaginal cytology, ovarian ultrasonography and semiquantitative estimation of progesterone using the Target Canine Ovulation Timing Kit (Biometallics, Princeton, NY). Insemination followed on the same day (two dogs), the next day (two dogs) or the day after next (two dogs). The first week, from day 0 to day 6 after insemination, was named week 1 after insemination. Gestation took 60-65 days after ovulation and 58-65 days after insemination. The bitches were examined every 2 or 3 days until birth, starting on day 16 after ovulation (week 3 after insemination). The chosen time between examinations was short because there is no description of the development of circulation in small animals. The number of fetuses was between two and seven $($ mean $=5, S D=2)$. The animals were not sedated. The hair of the ventral skin was (a)

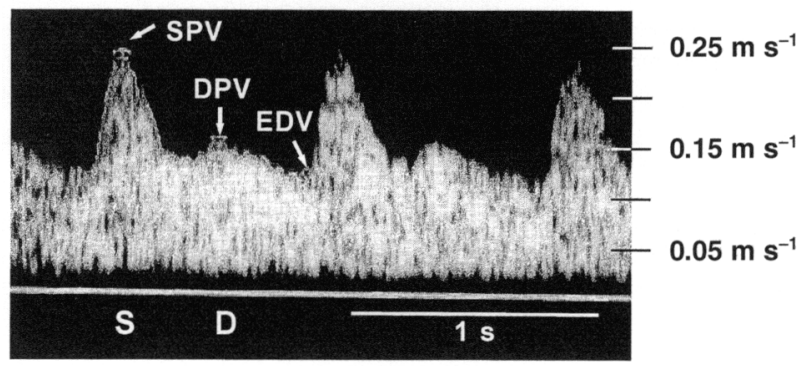

(b)

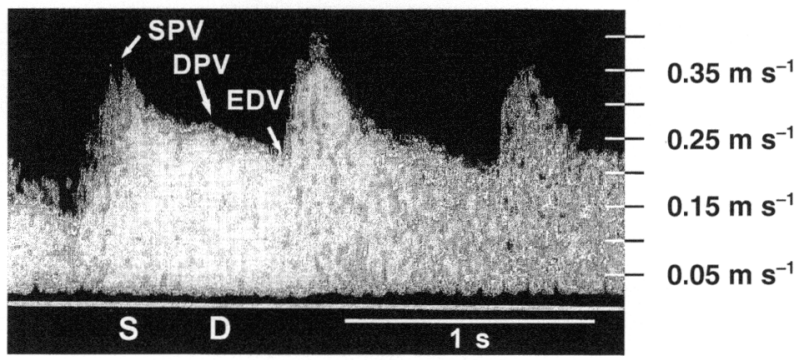

Fig. 2. Waveforms of canine small uteroplacental arteries in week 8 (a) and week 9 after insemination (b). SPV, systolic peak velocity; DPV, diastolic peak velocity; EDV, end-diastolic velocity; S, systole; D, diastole.

shaved at least three times during gestation. For examination, the dogs lay in dorsal or lateral recumbency on a soft baby's changing unit.

The ultrasonographic studies were performed with a Logic $500^{(i v)}$ ultrasound machine (General Electric, Kranzbuehler Medizinsysteme, Solingen) using a linear scanner of $7.5 \mathrm{MHz}$ and a convex probe of $5 \mathrm{MHz}$. The output power was $100 \%$, the wall filter $0.001-0.003 \mathrm{~m} \mathrm{~s}^{-1}$. Documentation was by video recorder, video printer and an integrated camera device for colour slides.

All gestational sacs, embryos and fetuses were examined and measured by two-dimensional ultrasonography. The circulation of two to four fetuses was evaluated by colourflow imaging and pulsed wave (PW) Doppler ultrasonography. In addition, PW Doppler measurements were taken within maternal uteroplacental arteries.

Small vessels, which are invisible in cross-sectional ultrasonography, were detected by colour-flow imaging. The blood flow pattern was recorded by PW Doppler ultrasonography using a Doppler gate 4-7 mm in length. The Doppler gate was placed exactly in the vessel or in the centre of the colour-coded blood flow. The Doppler gate usually embraced the entire vessel diameter. Manual aligning of the Doppler gate angle on the course of the vessel automatically corrects the measured blood flow velocity. Measurements with angles of $>65^{\circ}$ were subsequently disregarded.

The co-operation of the bitch limited the duration of one examination to $4-7 \mathrm{~h}$, including one or two intervals of about half an hour.

The blood flow was determined in small maternal uteroplacental vessels, which lay in the neighbourhood of one gestational sac or between two gestational sacs. The blood 
Table 2a. Blood flow velocities in canine small uteroplacental arteries

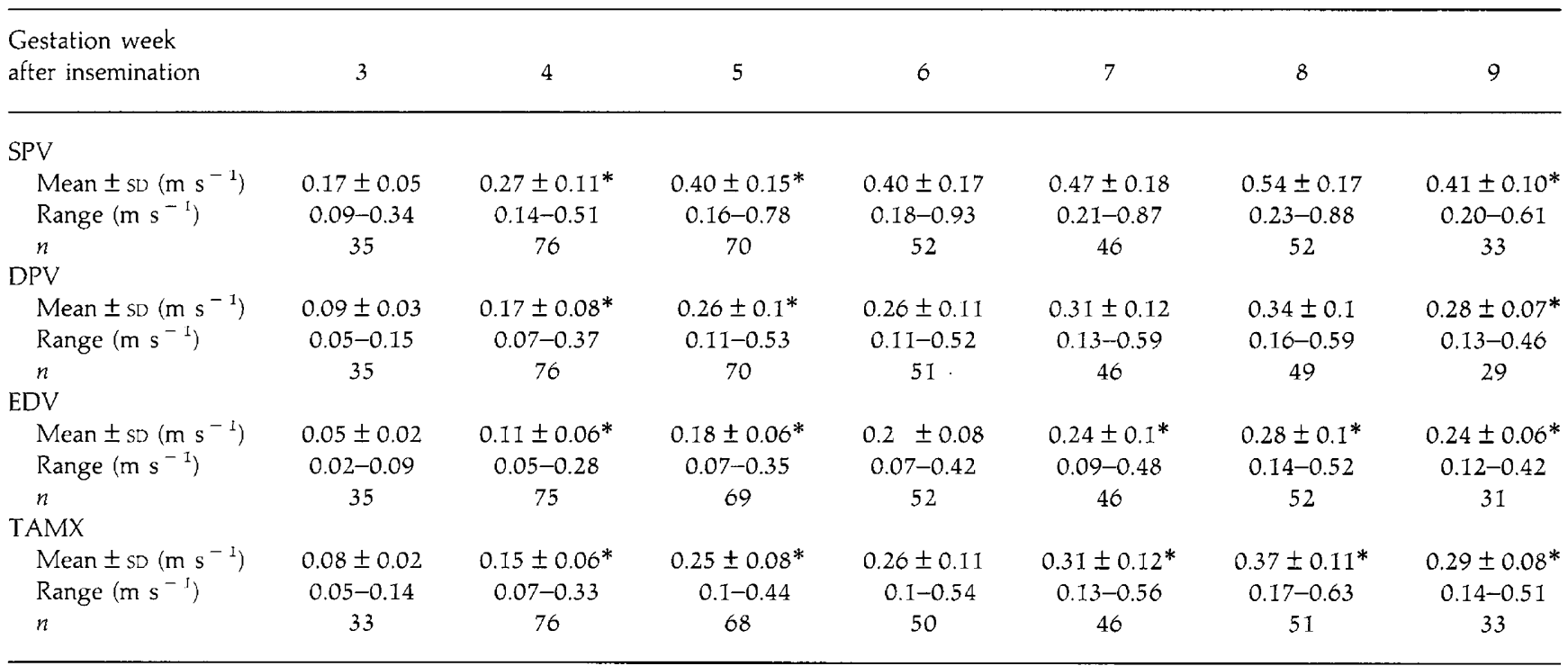

SPV, systolic peak velocity; DPV, diastolic peak velocity; EDV, end-diastolic peak velocity; TAMX, time averaged maximum velocity.

*Significantly different from previous week $(P<0.05)$.

Table $\mathbf{2 b}$. Indices in canine small uteroplacental arteries

\begin{tabular}{|c|c|c|c|c|c|c|c|}
\hline $\begin{array}{l}\text { Gestation week } \\
\text { after insemination }\end{array}$ & 3 & 4 & 5 & 6 & 7 & 8 & 9 \\
\hline Mean \pm SD & $1.47 \pm 0.31$ & $1.18 \pm 0.4^{*}$ & $0.99 \pm 0.21^{*}$ & $0.87 \pm 0.19^{*}$ & $0.82 \pm 0.15$ & $0.68 \pm 0.11^{*}$ & $0.64 \pm 0.1^{*}$ \\
\hline Range & $1.00-2.06$ & $0.57-2.4 \mathrm{I}$ & $0.57-1.43$ & $0.58-1.39$ & $0.56-1.24$ & $0.49-0.94$ & $0.45-0.85$ \\
\hline$n$ & 40 & 82 & 77 & 55 & 52 & 55 & 35 \\
\hline Range & $0.60-0.89$ & $0.49-0.86$ & $0.47-0.75$ & $0.44-0.71$ & $0.41-0.65$ & $0.38-0.58$ & $0.35-0.57$ \\
\hline$n$ & 44 & 80 & 76 & 55 & 52 & 55 & 35 \\
\hline \multicolumn{8}{|l|}{$A: B$} \\
\hline Mean $\pm S D$ & $3.28 \pm 0.86$ & $2.58 \pm 0.7^{*}$ & $2.27 \pm 0.29^{*}$ & $2.19 \pm 0.37$ & $2.1 \pm 0.26$ & $1.89 \pm 0.19^{*}$ & $1.84 \pm 0.22$ \\
\hline Range & $2.29-5.95$ & $1.58-5.31$ & $1.61-2.95$ & $1.59-3.09$ & $1.51-2.64$ & $1.59-2.33$ & $1.43-2.3$ \\
\hline$n$ & 40 & 83 & 73 & 53 & 53 & 57 & 37 \\
\hline
\end{tabular}

PI, pulsatility index; RI, resistance index; A:B, systolic peak velocity:end-diastolic velocity; S:D, systolic peak velocity:diastolic peak velocity.

*Significantly different from previous week $(P<0.05)$.

flow of relatively large uteroplacental arteries was not considered for calculation. The fetal circulation was evaluated in the umbilical artery at the beginning of the free umbilical cord near to the fetal abdominal wall, in the fetal descending aorta at the diaphragm and in the fetal common carotid artery in the cranial third of the neck. The absolute blood flow, velocities and velocity indices were measured and calculated to quantify the bloodstream (Table 1). The number of measurements and indices was influenced by factors such as changing animal compliance, mathematical realities (for example, no value when the denominator is 0 ) and technical problems (for example, large angles between blood flow and ultrasound beam).

In adult animals, the synchronous electrocardiogram (ECG) determined the systole (S) and diastole (D) in the Doppler waveforms. The systole (S) and diastole (D) of the fetal heart were identified by the distinct ventricle contractions, which were recognizable in cross-sectional ultrasound images from week 6 after insemination. The simultaneous registration of the left ventricle contractions and the Doppler waveforms within the aortic arch or the thoracic aorta allows the exact 

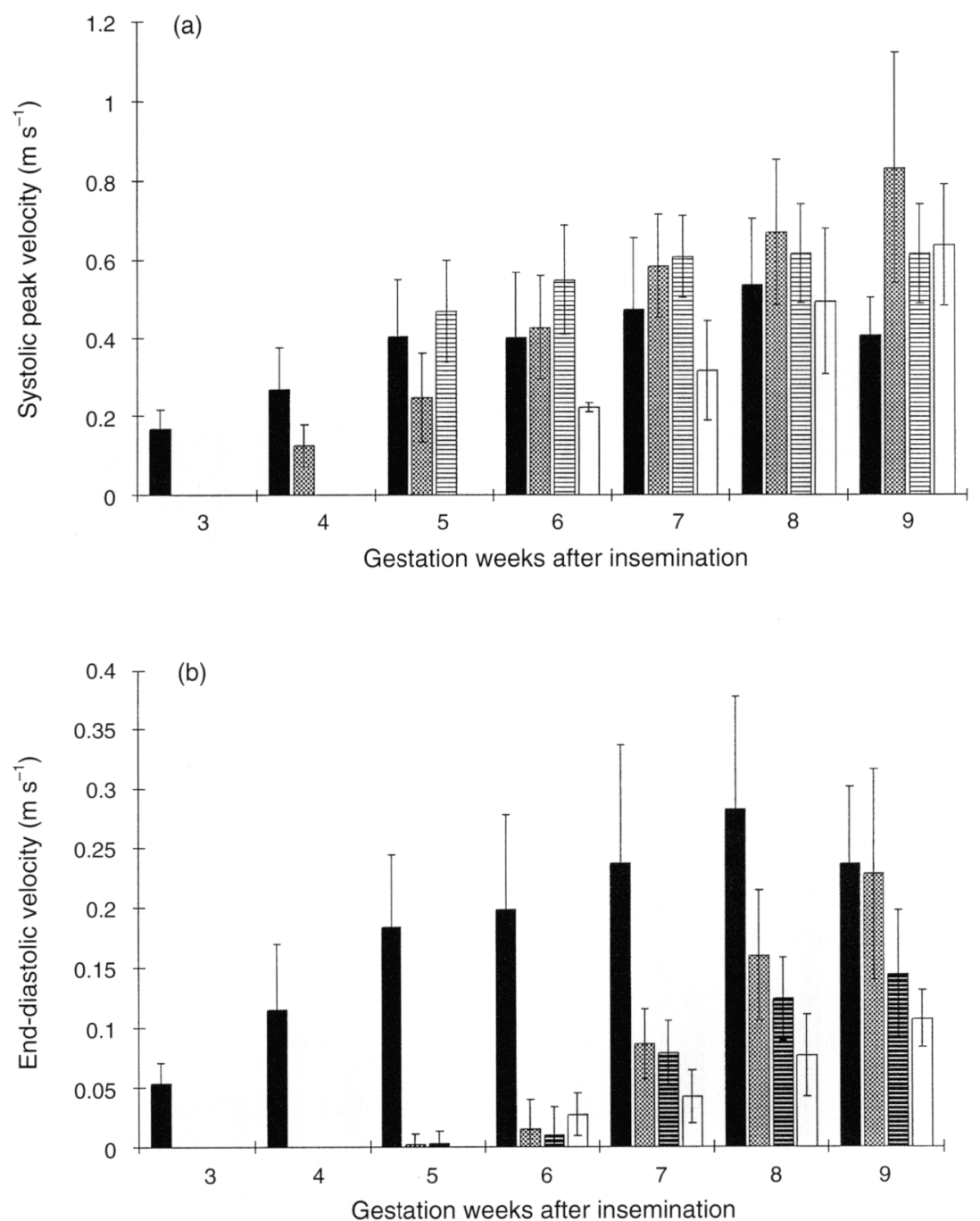

Fig. 3. Development of the systolic peak velocity (a) and the end-diastolic velocity (b) in canine maternal and fetal arteries (means $\pm \mathrm{SD}$ ). $\boldsymbol{\square}$, maternal uteroplacental arteries; umbilical arteries; 尽, fetal aorta; $\square$, fetal common carotid arteries.

determination of systole (S) and diastole (D). It was suggested that the waveforms of more peripheral arteries and of younger fetuses show a similiar relation to systole (S) and diastole (D).

\section{Statistical analyses}

Descriptive statistical analyses were performed using the computer programme Microsoft Excel 7.0. The absolute velocities and parameters were described as means $\pm S D$. The range and number of measurements ( $n$ ) are shown in the tables. Student's $t$ test (two group comparisons) was used to analyse the significance of differences of the mean values between 2 weeks and between the first and last weeks of gestation. Differences of $P<0.05$ were considered significant. A series of linear regression analyses was performed to compare the evidence of absolute velocities and indices. High correlation was considered if $r>0.9$; low correlation was considered if $0.5>r>0.25$.

\section{Results}

\section{Maternal uteroplacental arteries}

In week 3 after insemination, the gestational sac was first seen, using two-dimensional ultrasonography. It was characterized by anechoic fluid-filled, spherical uterine enlargement. Two hyperechoic lines in the gestational sac determined pregnancy. No embryonic mass was detected at this time. The maternal vessels in the direct neighbourhood of the gestational sac were detected by colour-flow imaging. The triphasic flow of the waveform showed steep increasing and decreasing systolic velocity, sometimes no or, mostly, very slow blood flow during early diastole, mid-diastolic peak velocity and relatively high end-diastolic velocity. A second forward diastolic peak velocity (DPV) existed between the first DPV and the end-diastolic velocity (EDV). The second DPV was slower than the first one. The respiratory arrhythmia of the bitch lead to an elongated diastole and therefore varying pulsatility index $(\mathrm{PI})$, resistance index (RI) 

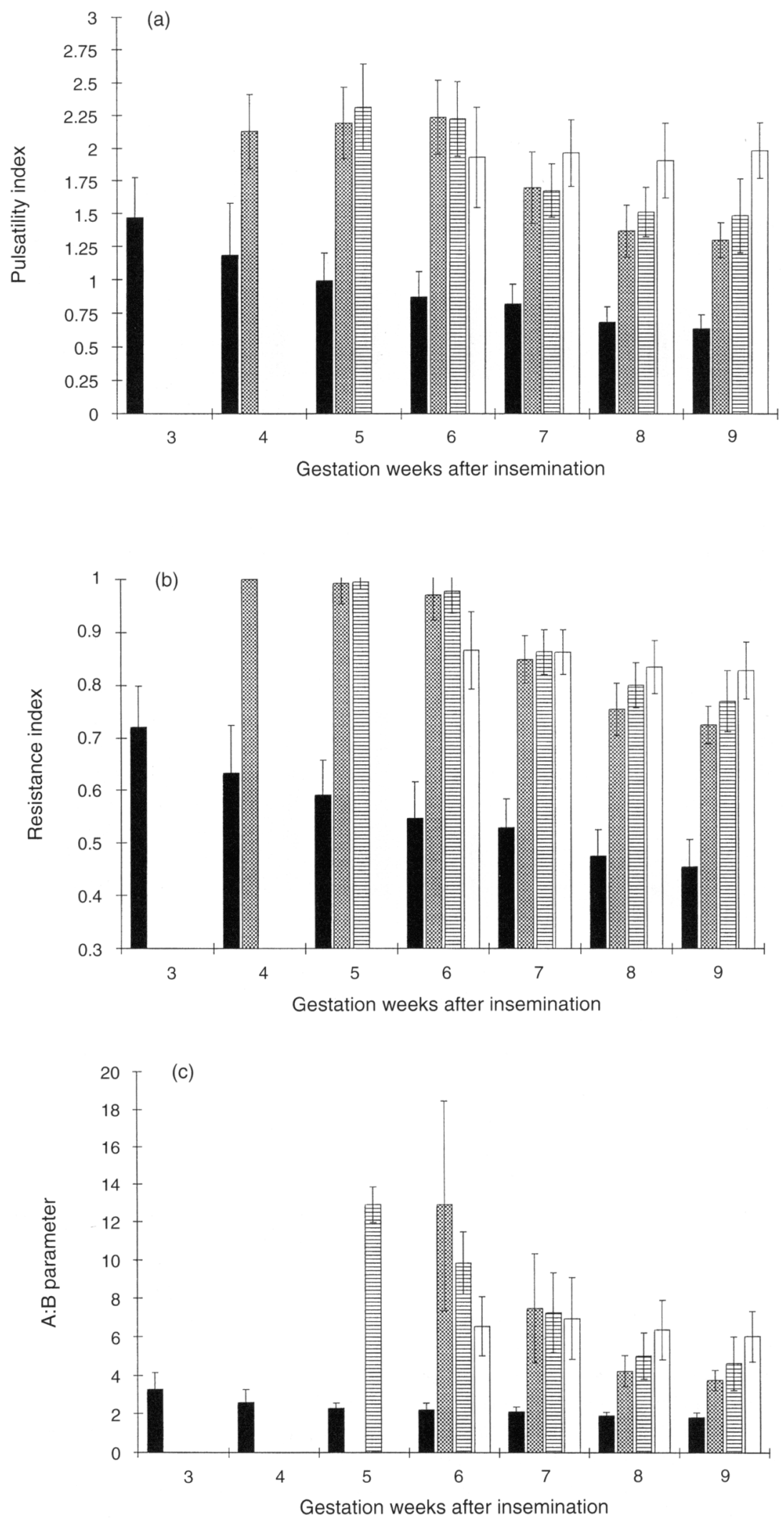

Fig. 4. Development of the (a) pulsatility index, (b) the resistance index and (c) the $A: B$ parameter (systolic peak velocity:end-diastolic velocity) in canine maternal and fetal arteries (means $\pm \mathrm{SD}$ ). $\mathbf{\square}$, maternal uteroplacental arteries; $\square$, umbilical arteries; 咠, fetal aorta; $\square$, fetal common carotid arteries. 


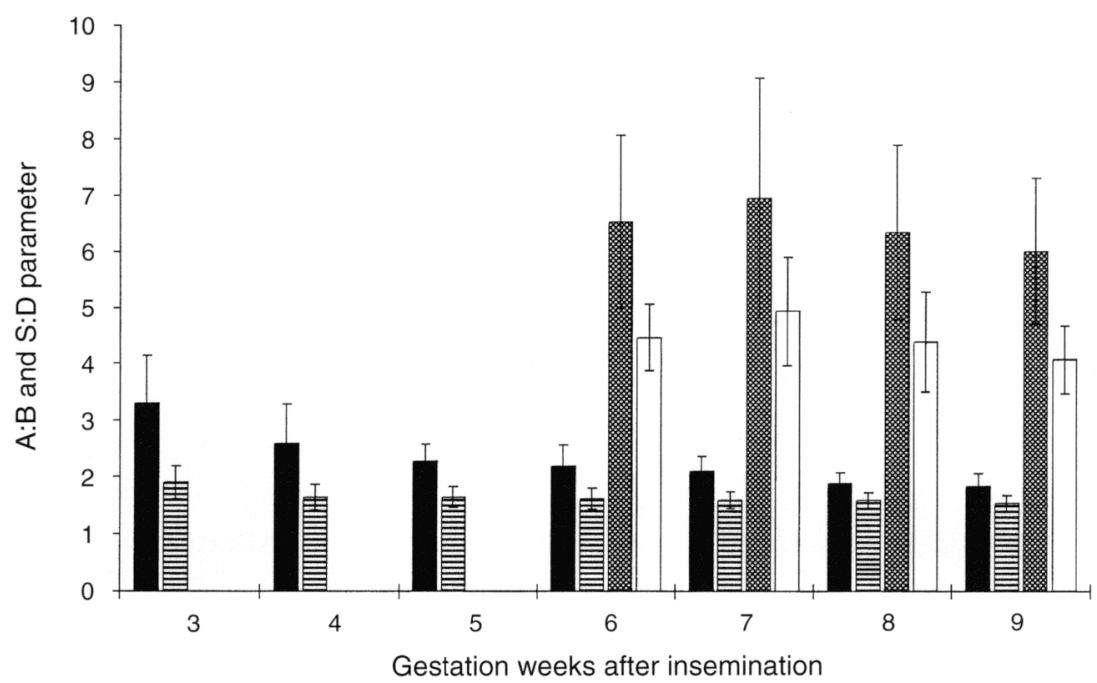

Fig. 5. Development of the $A: B$ (systolic peak velocity:end-diastolic velocity) and $S: D$ parameter (systolic peak velocity: diastolic peak velocity) in canine maternal uteroplacental arteries and fetal common carotid artery (means $\pm \mathrm{SD}$ ). $\mathbf{\square}, \mathrm{A}: \mathrm{B}$ in uteroplacental arteries; 馬, S:D in uteroplacental arteries; $\square, A: B$ in fetal common carotid arteries; $\square, S: D$ in fetal common carotid arteries.

and $A: B$ ratio (Fig. 1a,b). The PI, RI values and $A: B$ were higher in the long waveform during expiration. The S:D parameter (systolic peak velocity:diastolic peak velocity) showed less dependence on respiratory arrhythmia. Respiratory arrhythmia disappeared normally by week 6 after insemination.

Until week 4 after insemination, relatively large uteroplacental arteries of two bitches showed a triphasic blood flow with early diastolic back flow (rDPV, Fig. Ic). This triphasic blood flow was found in nearly all large uteroplacental arteries, which lay in the neighbourhood of the examined fetuses. The PI and A:B parameter of waveforms with rDPV were considerably higher than in flow patterns without back flow. From week 5 after insemination until birth, retrograde diastolic blood flow was not registered.

During advancing pregnancy, the waveform of the uteroplacental arteries became more monophasic (Fig. 2a). Early diastolic flow decreased or stagnation disappeared. The two diastolic peak velocities flattened until birth (Fig. 2b).

Throughout gestation, small uteroplacental vessels were detected by colour-flow imaging. Arteries were found within the uterine wall of one gestational sac during the first half of gestation. In the second half of pregnancy, the arteries were seen in the direct neighbourhood of the zonary placenta or between two gestational sacs.

The angle between the examined maternal vessel and the emitted ultrasound beam was $0-40^{\circ}$ in $72 \%$ of cases. Only $3 \%$ showed angles $>66^{\circ}$.

The systolic peak velocity (SPV) and EDV increased highly significantly until week 5 after insemination. In week 5 and 6 after insemination, the SPV and EDV remained constant. From week 6 to week 8 after insemination there was a significant increase of SPV and a small (not significant) increase of EDV. In the last week of gestation, all absolute velocities decreased significantly (Table 2a; Fig. 3).
The PI, RI, and A:B ratio decreased significantly from week 3 until birth (Table 2b; Figs 4 and 5). The decrease of the indices was steep (highly significant) in the first 2 weeks and more flattened (sometimes not significant) in the following weeks. The S:D parameter decreased distinctly (highly significantly) between weeks 3 and 4 . The decrease of the S:D parameter was less marked in the following weeks until birth (Fig. 5). The difference between $A: B$ and $S: D$ parameters decreased until term, represented by the distinctive flattening of DPV in the waveforms.

The developments of PI, RI and A:B correlated linearly with each other $(r>0.9)$ and with the S:D parameter $(r>0.6)$. The parameters PI and RI show low to moderate negative linear correlations with the absolute velocities SPV, DPV, TAMX and EDV ( $r_{\mathrm{PI} \text { of RI to SPV }}=-0.37, \quad r_{\mathrm{PI} \text { or RI to DPV }}=-0.48$, $\left.r_{\mathrm{Pl} \text { or RI to EDV }}=-0.57, r_{\mathrm{PI} \text { or R1 to } \mathrm{TAMX}}=-0.6\right)$.

Comparing the development of velocities and parameters in maternal uteroplacental arteries with those in fetal umbilical arteries, there was similar development with linear correlation in mother and fetus $\left(r_{\mathrm{PI}}=0.57, r_{\mathrm{RI}}=0.6 \mathrm{I}\right)$. The A:B ratio, SPV and EDV of uteroplacental arteries showed no or little correlation with the parameters in the feral umbilical artery $\left(r_{\mathrm{A}: \mathrm{B}}=0.27, r_{\mathrm{SPV}}=0.26, r_{\mathrm{EDV}}=0.38\right)$.

\section{Umbilical artery}

In week 4 after insemination, the umbilical artery was found in the free umbilical cord near the embryonic or fetal abdominal wall, using colour-flow imaging. Simultaneous registration of arterial and venous umbilical blood flow confirmed the exact position of a relatively large Doppler gate. During the first third of gestation, the umbilical blood flow had to be differentiated from the blood flow in the heart or within the aorta and caudal caval vein. The blood flow within the heart was less 
Table 3a. Blood flow velocities in the canine umbilical artery

\begin{tabular}{|c|c|c|c|c|c|c|}
\hline $\begin{array}{l}\text { Gestation week } \\
\text { after insemination }\end{array}$ & 4 & 5 & 6 & 7 & 8 & 9 \\
\hline Mean $\pm \mathrm{sD}\left(\mathrm{m} \mathrm{s}^{-1}\right)$ & $0.12 \pm 0.05$ & $0.25 \pm 0.11^{*}$ & $0.43 \pm 0.13^{*}$ & $0.58 \pm 0.13^{*}$ & $0.67 \pm 0.19^{*}$ & $0.83 \pm 0.29^{*}$ \\
\hline Range $\left(\mathrm{m} \mathrm{s}^{-1}\right)$ & $0.05-0.25$ & $0.10-0.58$ & $0.17-0.69$ & $0.29-0.87$ & $0.25-0.95$ & $0.24-1.45$ \\
\hline$n$ & 36 & 78 & 48 & 52 & 66 & 40 \\
\hline Range $\left(\mathrm{m} \mathrm{s}^{-1}\right)$ & $0-0$ & $0-0.06$ & $0-0.08$ & $0.03-0.17$ & $0.07-0.31$ & $0.07-0.46$ \\
\hline$n$ & 36 & 82 & 47 & 52 & 66 & 40 \\
\hline \multicolumn{7}{|l|}{ TAMX } \\
\hline Mean $\pm \mathrm{sD}\left(\mathrm{m} \mathrm{s}^{-1}\right)$ & $0.06 \pm 0.03$ & $0.11 \pm 0.05^{*}$ & $0.18 \pm 0.07^{*}$ & $0.30 \pm 0.07^{*}$ & $0.37 \pm 0.11^{*}$ & $0.47 \pm 0.17^{*}$ \\
\hline Range $\left(\mathrm{m} \mathrm{s}^{-1}\right)$ & $0.02-0.12$ & $0.04-0.26$ & $0.07-0.35$ & $0.16-0.49$ & $0.14-0.59$ & $0.14-0.79$ \\
\hline$n$ & 36 & 78 & 47 & 52 & 66 & 40 \\
\hline
\end{tabular}

SPV, systolic peak velocity; EDV, end-diastolic peak velocity; TAMX, time averaged maximum velocity.

*Significantly different from previous week $(P<0.05)$.

Table $\mathbf{3 b}$. Indices in the canine umbilical artery

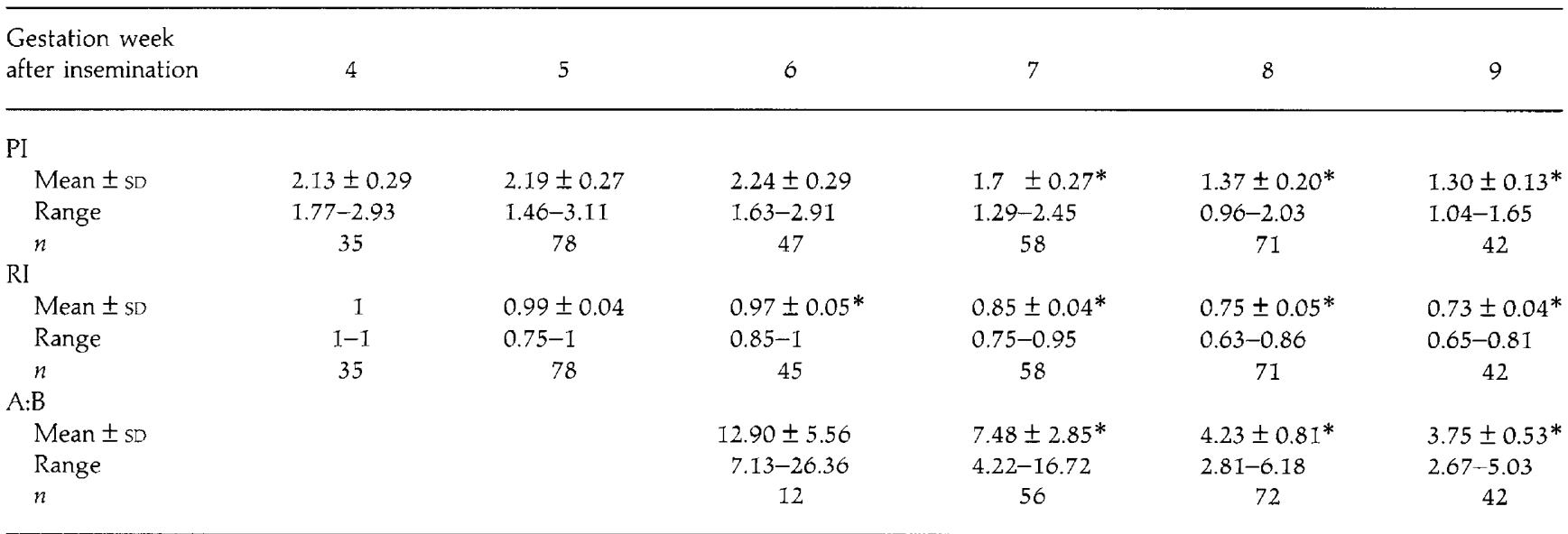

PI, pulsatility index; RI, resistance index; $A: B$, systolic peak velocity:end-diastolic velocity.

*Significantly different from previous week $(P<0.05)$.

uniform than in the umbilical vein. In contrast to the umbilical artery, the intracardial flow showed additional peaks between two systolic peak velocities. The waveform of the aorta and caudal caval vein was similar to that of the umbilical vessels. However, the colour-coded blood flow of the aorta and caudal cava vein could only be detected caudal and dorsal to the beating heart within the embryonic or fetal abdomen. During the last third of gestation, the umbilical vessels were already seen, using two-dimensional ultrasonography. Nevertheless, the exact position of the Doppler gate was determined by colour-flow imaging

The angle between the examined umbilical vessels and the emitted ultrasound beam was $0-40^{\circ}$ in $80 \%$ of the cases. Only $1 \%$ showed angles $>66^{\circ}$.

From week 4 to term, the SPV increased almost linearly with high significance (Table 3a; Fig. 3a). At week 4 after insemination, diastolic blood flow was not registered (Figs $3 \mathrm{~b}$ and $6 \mathrm{a}$ ).
At week 5 after insemination, 2 of 42 fetuses; and, at week 6 after insemination, 8 of 25 fetuses showed slow diastolic flow in some waveforms (Fig. 6b). During the following weeks there was diastolic blood flow in the umbilical artery of all fetuses (Fig. 6c). From week 6 after insemination until birth, the EDV increased significantly and almost linearly (Table 3a; Fig. 3b).

The PI increased consistently from week 5 to week 6 after insemination, and then decreased until birth (Table 3b; Fig. 4a). The RI $=1$ during week 4 and 5 after insemination. In the following weeks until birth it decreased (Table $3 \mathrm{~b}$; Fig. $4 \mathrm{~b}$ ). The $A: B$ ratio, first calculated in week 6 after insemination, decreased exponentially (Fig. 4c).

The development of the indices PI, RI and A:B correlated linearly ( $\left.r_{\mathrm{PI} \text { and RI }}>0.9, r_{\mathrm{A}: \mathrm{B} \text { and PI }}>0.8, r_{\mathrm{A}: \mathrm{B} \text { and RI }}>0.8\right)$. The correlation between RI and TAMX and EDV was also linear $\left(r_{\mathrm{RI} \text { and TAMX }}=-0.72, r_{\mathrm{RI} \text { and EDV }}=-0.8 \mathrm{I}\right)$. The PI and RI correlated less with the absolute velocity SPV $(r=-0.61)$. 
(a)

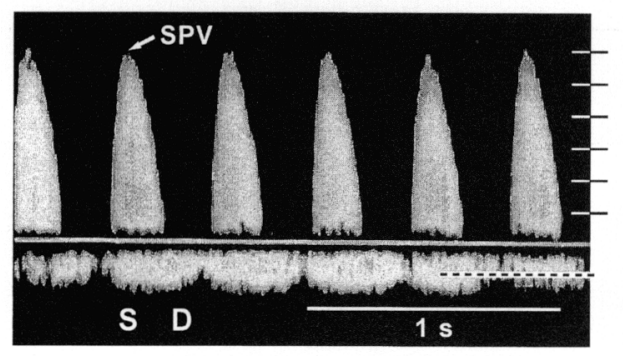

$0.25 \mathrm{~m} \mathrm{~s}^{-1}$

$0.15 \mathrm{~m} \mathrm{~s}^{-1}$

$0.05 \mathrm{~m} \mathrm{~s}^{-1}$

waveform of the umbilical vein

(b)

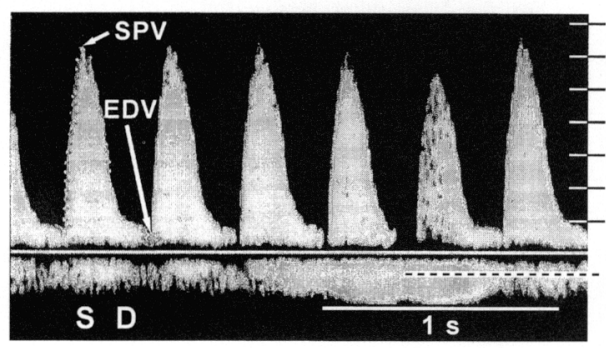

$0.7 \mathrm{~m} \mathrm{~s}^{-1}$

$0.5 \mathrm{~m} \mathrm{~s}^{-1}$

$0.3 \mathrm{~m} \mathrm{~s}^{-1}$

$0.1 \mathrm{~m} \mathrm{~s}^{-1}$

waveform of the umbilical vein

(c)

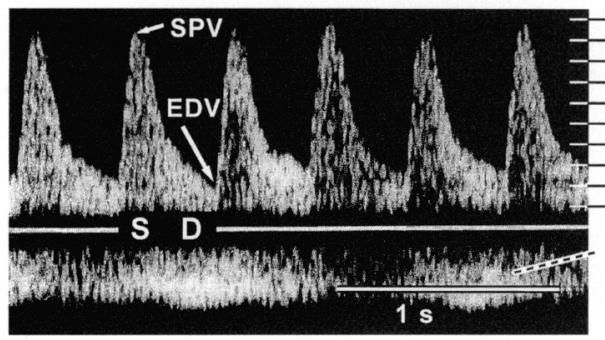

$0.9 \mathrm{~m} \mathrm{~s}^{-1}$

$0.7 \mathrm{~m} \mathrm{~s}^{-1}$

$0.5 \mathrm{~m} \mathrm{~s}^{-1}$

$0.3 \mathrm{~m} \mathrm{~s}^{-1}$

$0.1 \mathrm{~m} \mathrm{~s}^{-1}$

waveform of the umbilical vein

Fig. 6. Waveforms of the canine umbilical artery in week 5 (a), week 6 (b) and week 9 after insemination (c). SPV, systolic peak velocity; EDV, end-diastolic velocity; $\mathrm{S}$, systole; $\mathrm{D}$, diastole.

\section{Fetal descending aorta}

Beginning at week 5 after insemination, the blood flow could be detected regularly in the fetal aorta, using colour-flow imaging. In the last 2 weeks of gestation, the aorta was seen ventral to the vertebral column, using cross-sectional ultrasonography.

In $7 \%$ of cases, the angle between the examined fetal aortic blood flow and the emitted ultrasound beam was $0-40^{\circ}$. In $64 \%$ of cases, the angle was between $41^{\circ}$ and $65^{\circ}$, and $29 \%$ showed angles $>65^{\circ}$.

The SPV increased significantly from week 5 to week 7 after insemination. In the last 2 weeks before birth, the SPV remained constant (Table 4a; Fig. 3a). When first detected, no diastolic flow was observed in the majority of fetal descending aortae examined (Fig. 7a). Slow diastolic flow was measured in some waveforms (Fig. 7b) in 1 of 15 fetuses (week 5 after insemination), in 3 of 20 fetuses (week 6 after insemination) and in 19 of 20 fetuses (week 7 after insemination). From week 8 after insemination, all registered blood flows had at least a slow EDV, which increased significantly until birth (Table 4a; Figs $3 b$ and $6 c$ ). The RI index and A:B parameter decreased significantly during pregnancy (Table $4 \mathrm{~b}$; Fig. $4 \mathrm{~b}, \mathrm{c}$ ). The PI remained constant between week 5 and week 6 after insemination, decreased significantly from week 6 to week 8 and was constant again in the last week of gestation (Table $4 \mathrm{~b}$; Fig. 4a).

The development of the parameters PI, RI and A:B correlated $\left(r_{\mathrm{PI} \text { to RI }}=0.78, r_{\mathrm{PI} \text { or RI to A:B }}=0.44\right)$. The RI and PI had low negative correlation with SPV $(r=-0.3)$.

The development of the aortic PI and RI correlated well with the umbilical indices $\left(r_{\mathrm{PI}}=0.78, r_{\mathrm{RI}}=0.88\right)$. Linear correlation of aortic and umbilical A:B parameter was poor $\left(r_{\mathrm{A}: \mathrm{B}}=0.46\right)$ and the correlation coefficients of linear regressions of aortic and umbilical SPV and EDV were 0.47 and 0.8 , respectively.

\section{Fetal common carotid artery}

The fetal common carotid artery was first shown by colour-flow imaging in week 6 after insemination. In most fetuses examined, the biphasic waveform was composed of steep systolic increasing and decreasing velocity, and a slow diastolic velocity with flat, but separated DPV (Fig. 8a). This waveform was similar throughout pregnancy (Fig. 8b). When first detected, no diastolic flow was seen in the majority of fetal aortae examined. Slow diastolic flow was measured in 4 of 6 fetuses (week 6 after insemination) and in 19 of 20 fetuses (week 7 after insemination).

The angle between the examined common carotid arteries and the emitted ultrasound beam was $0-40^{\circ}$ in $15 \%$ of the registered flow patterns. The angle was $41-65^{\circ}$ in $51 \%$ of the cases, and $34 \%$ showed angles $>66^{\circ}$.

The SPV and EDV increased significantly from week 6 to week 9 after insemination (Table 5a; Fig. 3). The PI varied slightly (Table 5b; Fig. 4a), but showed no significant differences among the weeks of gestation. The RI decreased little from week 6 until birth (Table 5b; Fig. 4b). The A:B and S:D parameter decreased from week 6 to week 9. The weekly differences were not significant (Table 5 b; Figs $4 c$ and 5).

The PI and RI indices correlated linearly with the A:B and S:D parameters $(r>0.7)$. The linear correlation of $A: B$ and $S: D$ was approximately 0.6 . No correlation was found between the indices RI and PI and the absolute velocities $(r \leq 0.1)$.

There was little linear correlation between the development of the PI and RI indices and the A:B parameter in the umbilical and common carotid artery $(r<0.4)$. The SPV and EDV of the common carotid artery correlated with that of the umbilical artery little and moderately, respectively $\left(r_{\mathrm{SPV}}=0.47\right.$, $r_{\mathrm{EDV}}=0.74$ ).

\section{Discussion}

During normal canine pregnancy, Doppler waveforms of the uteroplacental artery, the umbilical artery, the fetal descending aorta and the fetal common carotid aorta were studied to evaluate the utero-fetal circulatory system and to obtain a physiological basis for further clinical studies in dogs.

The PW Doppler ultrasonographic measurements of the uteroplacental bloodstream are an important tool with which to evaluate materno-fetal circulation. The arterial waveforms depend on the proximal circulation, for example, cardiac cycles, 
Table 4a. Blood flow velocities in the canine fetal aorta

\begin{tabular}{|c|c|c|c|c|c|}
\hline $\begin{array}{l}\text { Gestation week } \\
\text { after insemination }\end{array}$ & 5 & 6 & 7 & 8 & 9 \\
\hline \multicolumn{6}{|l|}{ SPV } \\
\hline Mean $\pm \mathrm{sD}\left(\mathrm{m} \mathrm{s}^{-1}\right)$ & $0.47 \pm 0.13$ & $0.55 \pm 0.14^{*}$ & $0.61 \pm 0.10^{*}$ & $0.62 \pm 0.13$ & $0.62 \pm 0.13$ \\
\hline Range $\left(\mathrm{m} \mathrm{s}^{-1}\right)$ & $0.24-0.67$ & $0.17-0.75$ & $0.43-0.91$ & $0.43-0.89$ & $0.38-0.87$ \\
\hline$n$ & 28 & 36 & 38 & 41 & 23 \\
\hline \multicolumn{6}{|l|}{ EDV } \\
\hline Mean $\pm \mathrm{SD}\left(\mathrm{m} \mathrm{s}^{-1}\right)$ & $0+0.01$ & $0+0.02$ & $0.09 \pm 0.03$ & $0.12 \pm 0.03^{*}$ & $0.14 \pm 0.05$ \\
\hline Range $\left(\mathrm{m} \mathrm{s}^{-1}\right)$ & $0-0.05$ & $0-0.08$ & $0-0.12$ & $0.07-0.20$ & $0.06-0.27$ \\
\hline$n$ & 30 & 40 & 38 & 41 & 23 \\
\hline \multicolumn{6}{|l|}{ TAMX } \\
\hline Mean $\pm \mathrm{so}\left(\mathrm{m} \mathrm{s}^{-1}\right)$ & $0.20 \pm 0.07$ & $0.24 \pm 0.07^{*}$ & $0.31 \pm 0.05^{*}$ & $0.32 \pm 0.06$ & $0.33 \pm 0.08$ \\
\hline Range $\left(\mathrm{m} \mathrm{s}^{-1}\right)$ & $0.09-0.34$ & $0.06-0.39$ & $0.22-0.47$ & $0.20-0.43$ & $0.2-0.49$ \\
\hline$n$ & 28 & 36 & 38 & 41 & 23 \\
\hline
\end{tabular}

SPV, systolic peak velocity; EDV, end-diastolic peak velocity; TAMX, time averaged maximum velocity.

* Significantly different from previous week $(P<0.05)$.

Table $\mathbf{4 b}$. Indices in the canine fetal aorta

\begin{tabular}{|c|c|c|c|c|c|}
\hline $\begin{array}{l}\text { Gestation week } \\
\text { after insemination }\end{array}$ & 5 & 6 & 7 & 8 & 9 \\
\hline \multicolumn{6}{|l|}{$\mathrm{Pl}$} \\
\hline Mean $\pm S D$ & $2.32 \pm 0.33$ & $2.23 \pm 0.29$ & $1.68 \pm 0.2^{*}$ & $1.51 \pm 0.19^{*}$ & $1.49 \pm 0.28$ \\
\hline Range & $1.77-3.08$ & $1.65-2.83$ & $1.04-2.47$ & $1.16-2.04$ & $1.00-2.03$ \\
\hline$n$ & 32 & 44 & 54 & 74 & 37 \\
\hline \multicolumn{6}{|l|}{ RI } \\
\hline Mean $\pm \mathrm{SD}$ & $1-0.01$ & $0.98 \pm 0.04 *$ & $0.86 \pm 0.04^{*}$ & $0.80 \pm 0.04 *$ & $0.77 \pm 0.06^{*}$ \\
\hline Range & $0.93-1$ & $0.89-1$ & $0.76-1$ & $0.71-0.94$ & $0.64-0.89$ \\
\hline$n$ & 34 & 44 & 54 & 74 & 37 \\
\hline \multicolumn{6}{|l|}{$A: B$} \\
\hline Mean $\pm S D$ & $12.9 \pm 0.94$ & $9.84 \pm 1.62 *$ & $7.26 \pm 2.08^{*}$ & $5 \pm 1.2^{*}$ & $4.62 \pm 1.39$ \\
\hline Range & $12.24-13.57$ & $8.07-12.91$ & $4.2-15.53$ & $3.15-8.6$ & $2.59-8.69$ \\
\hline$n$ & 2 & 9 & 49 & 69 & 37 \\
\hline
\end{tabular}

PI, pulsatility index; RI, resistance index; $A: B$, systolic peak velocity:end-diastolic velocity.

*Significantly different from previous week $(P<0.05)$.

cardiac output and aortic wall elasticity of the bitch, and on the distal receiving bed (Evans et al., 1980). In particular, the development of the maternal and fetal placental vascularization influences the maternal blood flow pattern. During early gestation, the triphasic blood flow (high resistance flow) with early diastole flow deceleration in small vessels and retrograde diastolic flow in some larger uteroplacental arteries shows the relatively high resistance in the arterioles and capillaries of the uterine wall. At this time (weeks 3 and 4 after insemination) the apposition is just beginning and the placenta is in the initial stage (Noden and De Lahunta, 1985). The relatively high values of RI, PI, A:B and S:D in week 3 after insemination are quantitative proof of this. During implantation and progressive development of the placental vascularization, the indices decrease distinctly from week 3 to week 4 after insemination. In week 4 after insemination, the umbilical artery can be detected by colour Doppler imaging for the first time. After week 4 , the further decrease of the indices becomes less steep.
The significant decrease of the PI index and A:B parameter during the first third of gestation, and the smaller decrease during the rest of gestation, is similar to the development of the blood flow pattern in human pregnancy (Schulman et al., 1986; Funk et al., 1995). The need to intensify maternal placental circulation leads to increasing SPV and EDV until week 8 after insemination. The linear increase of SPV is also typical in early human pregnancy (Jurkovic et al., 1991; Funk et al., 1995). In the last week of gestation, the decrease of absolute velocities SPV and EDV is typical in dogs. It probably indicates the approaching birth and correlates with the placental oedema of the placenta at days 62-64 after ovulation (week 9 after insemination; Guenzel-Apel et al., 1996).

The disadvantage of transcutaneous PW Doppler measurements in canine uteroplacental arteries is that it is impossible to repeat examinations within the same vessel at the same position. In addition, the exact anatomical correlate is obscure. The shapes of waveforms in small branches of the human 
(a)

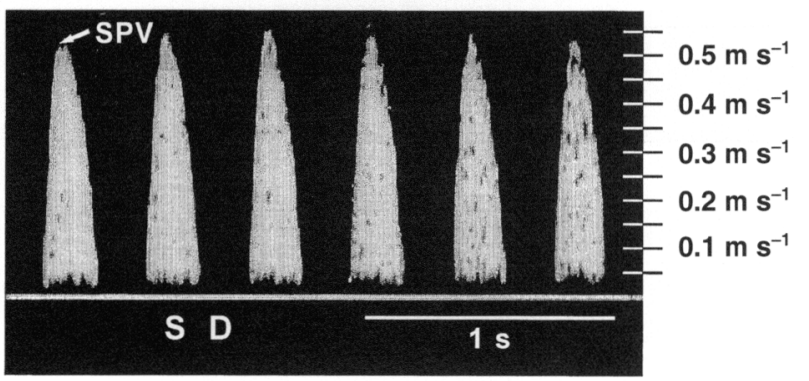

(b)

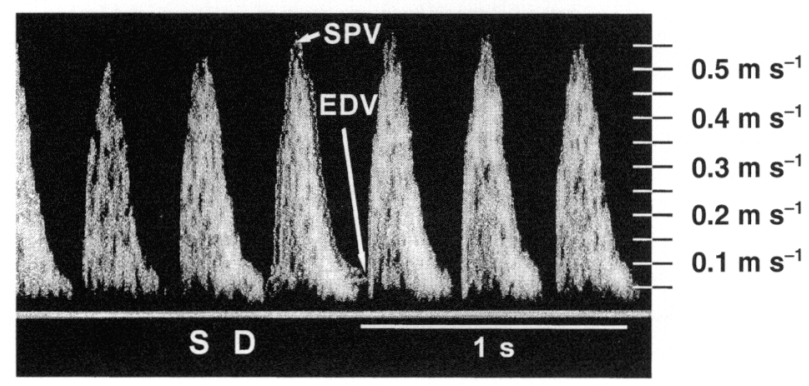

(c)

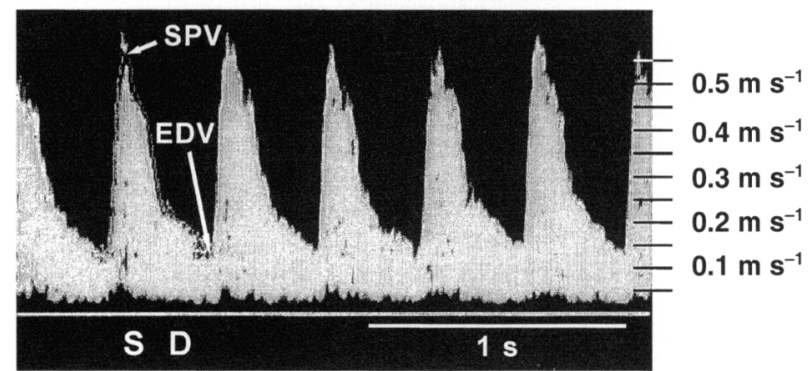

Fig. 7. Waveforms of the canine fetal descending aorta in week 5 (a), week 7 (b) and week 9 after insemination (c). SPV, systolic peak velocity; EDV, end-diastolic velocity; $S$, systole; $D$, diastole.

uterine arteries clearly depend on the position of the Doppler gate within the uterine artery or different branches (Deutinger, 1992). In dogs, the exact determination of Doppler gate position is more difficult than in humans because of the small size of structures. In human obstetrics, transvaginal Doppler ultrasonography of both uterine arteries is a good alternative method to transcutaneous uterine ultrasonography (Deutinger et al., 1988; Deutinger, 1992). In small animals, the bilateral Doppler measurements within the main uterine arteries provide less information on fetal developmental changes, because the multiparous bitch has usually implanted many fetuses in each uterine horn.

The value of Doppler measurements in maternal uterine arteries or branches is unquestionable in human obstetrics. The method is suitable for screening in the last trimester of human pregnancy. Doppler ultrasound seems to be a very good diagnostic tool, especially in the case of gestation hypertension, preeclampsia or fetal growth retardation (Schulman, 1987; Deutinger, 1992). (a)

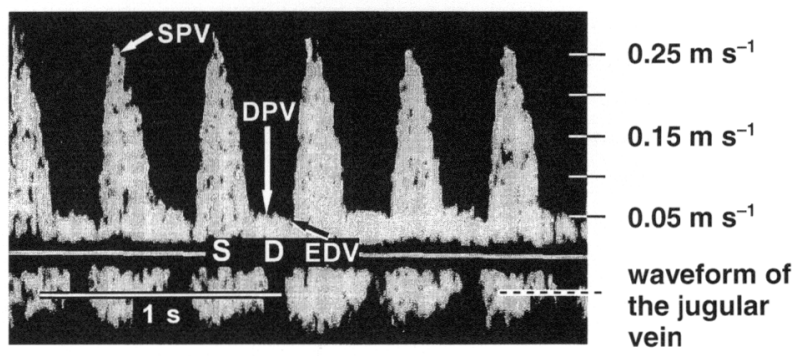

(b)

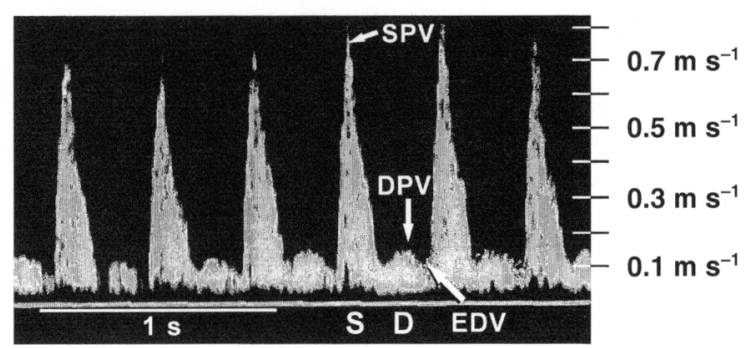

Fig. 8. Waveforms of the canine fetal common carotid artery in week 6 (a) and week 9 after insemination (b). SPV, systolic peak velocity; DPV, diastolic peak velocity; EDV, end-diastolic velocity; S, systole; D, diastole.

An atypical waveform in a uteroplacental artery in bitches also indicates problems. In the last third of canine pregnancy, an early diastolic blood flow stagnation correlated with a retarded puppy, which died in the first days of life (Poulsen Nautrup, 1996). Nevertheless, false positive results of Doppler measurements are well known in human uterine arteries (Jacobson et al., 1990). Further studies are needed to show the clinical value of Doppler ultrasonography of uteroplacental vessels for diagnosis and prognosis during canine pathological gestation.

The umbilical and fetal aortic arterial circulation depends on the fetal heart activity and the development of the fetal placenta. The waveforms provide information about the changing compliance of fetal vessels (Kuenzel, 1992). In weeks 5 and 6 after insemination, absent diastolic blood flow and high values of $\mathrm{PI}$ and $\mathrm{RI}$ indicate high resistance in the canine placenta. The full development of the fetal placenta leads to decreasing resistance and, therefore, to decreasing indices in the fetal descending aorta and umbilical artery. In the last third of gestation, these arteries show increasing diastolic blood flow. Absent or retrograde diastolic blood flow was not recorded. These results are similar to those in human obstetrics (Arabin et al., 1987; Hueneke et al., 1995).

The SPV of the canine descending aorta remains constant in the last 2 weeks of gestation. This finding is similar to that of the abdominal aorta in the human fetus, which shows constant SPV in the last trimester of human pregnancy (Kuenzel, 1992).

The PI and RI indices of the canine umbilical artery correlate with those of the fetal aorta, similar to the correlation of PI and RI in human fetal vessels (Thompson et al., 1988). While the RI and PI of the umbilical artery correlate with those of the fetal aorta, the A:B shows no correlation between the two vessels in the dog. Nevertheless, the similar development of umbilical 
Table 5a Blood flow velocities in the canine fetal common carotid artery

\begin{tabular}{|c|c|c|c|c|}
\hline $\begin{array}{l}\text { Gestation week } \\
\text { after insemination }\end{array}$ & 6 & 7 & 8 & 9 \\
\hline \multicolumn{5}{|l|}{ SPV } \\
\hline Mean $\pm \mathrm{SD}\left(\mathrm{m} \mathrm{s}^{-1}\right)$ & $0.22 \pm 0.01$ & $0.32 \pm 0.13^{*}$ & $0.49 \pm 0.19^{*}$ & $0.64 \pm 0.15^{*}$ \\
\hline Range $\left(\mathrm{m} \mathrm{s}^{-1}\right)$ & $0.20-0.24$ & $0.13-0.64$ & $0.19-0.78$ & $0.32-0.93$ \\
\hline$n$ & II & 40 & 33 & 29 \\
\hline \multicolumn{5}{|l|}{ DPV } \\
\hline Mean $\pm \mathrm{so}\left(\mathrm{ms}^{-1}\right)$ & $0.05 \pm 0.01$ & $0.06 \pm 0.02 *$ & $0.11 \pm 0.05^{*}$ & $0.16 \pm 0.03^{*}$ \\
\hline Range $\left(\mathrm{m} \mathrm{s}^{-1}\right)$ & $0.04-0.06$ & $0.03-0.11$ & $0.04-0.21$ & $0.09-0.21$ \\
\hline$n$ & 7 & 30 & 31 & 26 \\
\hline \multicolumn{5}{|l|}{ EDV } \\
\hline Mean $\pm \mathrm{SD}\left(\mathrm{m} \mathrm{s}^{-1}\right)$ & $0.03 \pm 0.02$ & $0.04 \pm 0.02 *$ & $0.08 \pm 0.03 *$ & $0.11 \pm 0.02 *$ \\
\hline Range $\left(\mathrm{m} \mathrm{s}^{-1}\right)$ & $0-0.05$ & $0-0.11$ & $0.03-0.15$ & $0.07-0.14$ \\
\hline$n$ & 11 & 40 & 33 & 29 \\
\hline \multicolumn{5}{|l|}{ TAMX } \\
\hline Mean $\pm \mathrm{SD}\left(\mathrm{m} \mathrm{s}^{-1}\right)$ & $0.10 \pm 0.01$ & $0.14 \pm 0.06^{*}$ & $0.22 \pm 0.09^{*}$ & $0.27 \pm 0.07 *$ \\
\hline Range $\left(\mathrm{m} \mathrm{s}^{-1}\right)$ & $0.08-0.13$ & $0.06-0.33$ & $0.08-0.39$ & $0.16-0.38$ \\
\hline$n$ & 11 & 40 & 33 & 29 \\
\hline
\end{tabular}

SPV, systolic peak velocity; DPV, diastolic peak velocity; EDV, end-diastolic peak velocity; TAMX, time averaged maximum velocity.

*Significantly different from previous week $(P<0.05)$.

Table 5b. Indices in the canine fetal common carotid artery

\begin{tabular}{|c|c|c|c|c|}
\hline $\begin{array}{l}\text { Gestation week } \\
\text { after insemination }\end{array}$ & 6 & 7 & 8 & 9 \\
\hline \multicolumn{5}{|l|}{ PI } \\
\hline Mean \pm SD & $1.93 \pm 0.39$ & $1.96 \pm 0.26$ & $1.91 \pm 0.29$ & $1.98 \pm 0.21$ \\
\hline Range & $1.54-2.73$ & $1.55-2.62$ & $1.07-2.43$ & $1.57-2.43$ \\
\hline$n$ & 10 & 38 & 41 & 33 \\
\hline \multicolumn{5}{|l|}{ RI } \\
\hline Mean $\pm \mathrm{sD}$ & $0.87 \pm 0.07$ & $0.86 \pm 0.04$ & $0.83 \pm 0.05^{*}$ & $0.83 \pm 0.05$ \\
\hline Range & $0.81-1$ & $0.81-1$ & $0.64-0.92$ & $0.6-0.95$ \\
\hline$n$ & 10 & 38 & 43 & 33 \\
\hline \multicolumn{5}{|l|}{$A: B$} \\
\hline Mean \pm SD & $6.54 \pm 1.54$ & $6.96 \pm 2.13$ & $6.35 \pm 1.56$ & $6.02 \pm 1.31$ \\
\hline Range & $5.05-10.08$ & $4.37-14.02$ & $2.71-9.79$ & $3.79-8.8$ \\
\hline$n$ & 8 & 36 & 43 & 31 \\
\hline \multicolumn{5}{|l|}{ S:D } \\
\hline Mean $\pm \mathrm{SD}$ & $4.46 \pm 0.60$ & $4.95 \pm 0.96$ & $4.40 \pm 0.89 *$ & $4.09 \pm 0.60$ \\
\hline Range & $3.88-5.47$ & $3.05-6.74$ & $2.28-6.13$ & $3.05-5.24$ \\
\hline$n$ & 7 & 28 & 38 & 30 \\
\hline
\end{tabular}

PI, pulsatility index; RI, resistance index; A:B, systolic peak velocity:end-diastolic velocity; S:D, systolic peak velocity:diastolic peak velocity.

${ }^{*}$ Significantly different from previous week $(P<0.05)$.

and aortic blood flow allows an evaluation of the blood flow at only one location. The uterine artery can be detected earlier and easier than the fetal aorta. In addition, the angle between ultrasound beam and blood flow is usually smaller in the uterine artery than in the fetal aorta.

The linear correlation of all indices is not given between the fetal umbilical artery and the common carotid artery. The measurement of the fetal common carotid artery has produced new information. Shortly before term, the Doppler ultrasono- graphic measurement of the cerebral arterial blood flow is a good tool in human obstetrics to estimate possible perinatal hypoxia and acidosis (Arabin et al., 1992). The waveform of the canine arteria carotis communis resembles that in the human, but the development of the indices in the human common carotid artery is different (Arabin et al., 1992).

Cerebral development requires a constant supply of nutrients and oxygen. Therefore, the relationship between systolic and diastolic bloodstream, described by indices, is 
relatively low at the time of first detection and remains almost constant throughout gestation. The undetectable diastolic blood flow in some fetuses in weeks 6 and 7 may be attributed to technical problems. It is possible that the diastolic blood flow was as high as the filter used, so that no EDV was registered.

In maternal and fetal arteries, the deviation of the measured velocities is high because of the great biological variability and many technical errors. In particular, the large angles between the ultrasound beam and the fetal aortas and fetal common carotid arteries lead to measurement errors, if manual correction is not exact. Depending on the maternal respiration and fetal movement, the constantly shifting position of vessel and Doppler gate impedes an exact angle correction. Therefore, angles $>65^{\circ}$ have to be disregarded. Nevertheless, the registered velocities provide additional data. The decrease of maternal uteroplacental SPV and EDV in the final weeks of gestation is particularly noteworthy.

The disadvantage of Doppler ultrasonography in canine obstetrics is the long time spent on an examination. Limiting the Doppler ultrasonographic calculation to the PI and RI index within maternal uteroplacental and fetal umbilical arteries would shorten the time. Only suspicion of fetal distress or outcome should then lead to more detailed measurements. Another problem of ultrasonographic studies in bitches is that fetuses may be overlooked. Nevertheless, this method may become important for monitoring and prognosis during a problematic pregnancy, as it is in human obstetrics.

This work was supported by a grant of the Deutsche Forschungsgemeinschaft, Bonn. The author thanks A-R. Guenzel-Apel, Institute for Reproductive Medicine, Veterinary School Hannover, for her courtesy in placing the bitches and an examination room at my disposal; R. Pabst for support and advice; and S. Fryk for the correction of the English text.

\section{References}

Alfirevic Z and Neilson JP (1995) Doppler ultrasonography in high-risk pregnancies: systematic review with meta-analysis American journal of Obstetrics and Gynecology 172 1379-1387

Arabin B, Bergmann PL and Saling E (1987) Simultaneous assessment of blood flow velocity waveforms in uteroplacental vessels, the umbilical artery, the fetal aorta, and the fetal common carotid artery Fetal Therapy 2 17-26

Arabin B, Hansmann M and Weitzel HK (1992) Zerebrales Blutflußprofil beim Fetus Gynaekologe 25 324-331

Arbeille B, Fignon A, Bosc M and Bodart S (1994) Modifications des circulations utéro-placentaire et cérébrale foetales induites par la nicotine chez le fetus ovin Journal de Gynecologie, Obstetrique et Biologie de la Réproduction, Paris 23 51-56

Barr FJ (1988) Pregnancy diagnosis and assessment of fetal viability in the dog: a review Journal of Small Animal Practice 29 647-656

Bondestam S, Alitalo I and Karkkainen M (1983) Real-time ultrasound pregnancy diagnosis in the bitch Journal of Small Animal Practice 24 145-151

Bondestam S, Karkkainen M, Alitalo I and Forss M (1984) Evaluating the accuracy of canine pregnancy diagnosis and litter size determination using real-time ultrasound Acta Veterenaria Scandinavica 25 327-332

Bruner JP, Sheppard CG, Reed GW and Boehm FH (1994) The umbilical artery Doppler ultrasonographic gradient confirmation, cause, and comparison of continuous-wave and duplex ultrasonographic pulsed-wave measurements Journal of Perinatology 14 386-392

Deutinger J (1992) Physiologie des Doppler-Flusses in maternalen Gefaessen waehrend der Schwangerschaft Gynaekologe 5 284-291
Deutinger J, Rudelstorfer R and Bernaschek G (1988) Vaginosonographic velocimetry of both main uterine arteries by visual vessel recognition and pulsed Doppler method during pregnancy American Journal of Obstetrics and Gynecology 159 1072-1076

Engelke A and Gassner G (1996) Gefaeße und Nerven. In Atlas und Lehrbuch der Ultraschalldiagnostik bei Hund und Katze pp 360-362 Eds C Poulsen Nautrup and R Tobias. Schluetersche Verlagsanstait, Hannover

England GCW (1993) Ultrasonographic imaging of spontaneous embryonic resorption in the bitch Journal of Reproduction and Fertility Supplement $\mathbf{4 7 5 5 2}$

England GCW and Allen WE (1990) Studies on canine pregnancy using B-mode ultrasound: diagnosis of early pregnancy and the number of conceptuses Journal of Small Animal Practice 31 321-323

England GCW, Allen WE and Porter DJ (1990) Studies on canine pregnancy using B-mode ultrasound: development of the conceptus and determination of gestational age Joumal of Small Animal Practice 31 324-329

Evans DH, Barrie WW, Asher MJ, Bentley S and Bell PRF (1980) The relationship between ultrasonic pulsatility index and proximal arterial stances in a canine model Circulation Research 46 470-475

Fitzgerald DE and Drumm JE (1977) Non-invasive measurement of human fetal circulation using ultrasound: a new method British Medical Journal 2 1450-1451

Funk A, Joern H and Meletiadon A (1995) Transvaginale Dopplersonographie in der Fruehschwangerschaft - Normwertkurven und Vergleich mit einem Risikokollektiv mit drohender Fehlgeburt Zeitschrift fuer Geburtshilfe und Neonatologie 199 2-7

Gonser M (1996) Dopplersonographie in der Schwangerenvorsorge Zeitschrift fuer Geburtshilfe und Neonatologie 200 69-71

Gonser M and Vetter K (1995) Diagnostische und klinische Wertigkeit der Dopplersonographie in der Geburtshilfe Geburtshilfe und Frauenheilkunde 55 605-615

Gosling RG and King DH (1974) Arterial assessment by Doppler-shift ultrasound Proceedings of the Royal Society of Medicine 67 447-449

Guenzel-Apel A-R, Heinze B and Schaefer D (1996) Bestimmung des Gestationsalters. In Atlas und Lehrbuch der Ulitraschalldiagnostik bei Hund und Katze pp 304-308 Eds C Poulsen Nautrup and R Tobias. Schluetersche Verlagsanstalt, Hannover

Hueneke B, Holst A, Schroeder HJ and Carstensen MH (1995) Normalbereiche fuer die relativen Doppler-Indizes A:B-Ratio, Resistance-Index und Pulsatilitaetsindex der Arteria uterina und Arteria umbilicalis bei ungestoerter Schwangerschaft. Eine Laengsschnittstudie Geburtshilfe und Frauenheilkunde 55 616-622

Irion GL and Clark K-E (1990) Direct determination of the ovine fetal umbilical artery blood flow waveform American Journal of Obstetrics and Gynecology 162 541-549

Jacobsen S, Imhof R, Manning N, Mannion V, Little D, Rey E and Redman C (1990) The value of Doppler assessment of the uteroplacental circulation in predicting preeclampsia or uterine growth retardation American Journal of Obstetrics and Gynecology 162 110-114

Jurkovic D, Jauniaux E, Kurjak A, Hustin J, Campbell S and Nicolaides H (1991) Transvaginal color Doppler assessment of the uteroplacental circulation in early pregnancy Obstetrics and Gynecology 77 365-369

Kuenzel W (1992) Die Blutflußgeschwindigkeit und der Blutfluß in den Gefaeßen der Nabelschnur und in der Aorta des Feten waehrend der Schwangerschaft Gynaekologe 5 292-296

Meyberg GC and Sohn C (1995) Liefert die Messung von Absolutgeschwindigkeiten bei der Doppleruntersuchung von Schwangeren wichtige Zusatzinformationen? Zentralblatf für Gynaekologie 117 297-299

Molendijk L, Malburg I and Kopecky P (1995) Dopplersonographische Untersuchungen bei Plazentainsuffizienz als Hinweis fuer die Effektivitaet der Haemodilutionstherapie Zeitschrift fuer Geburtshilfe und Neonatologie 199 $18-22$

Morrow KL, Salman MD, Lappin MR and Wrigley R (1996) Comparison of the restive index to clinical parameters in dogs with renal disease Veterinary Journal of Radiology and Ultrasound 37 193-199

Noden DM and De Lahunta A (1985) The Embryology of the Domestic Animals Developmental Mechanisms and Malformations Williams and Wilkins, Baltimore, London

Nyland TG, Fisher PE, Overspike M, Hornhof WH and Olander HJ (1993) Diagnosis of urinary tract obstruction in dogs using duplex Doppler ultrasonography Veterinary Journal of Radiology and Ultrasound 34 348-352

Poulsen Nautrup C (1996) Duplexsonographie. In Atlas und Lehrbuch der Ultraschalldiagnostik bei Hund und Katze pp 314-322 Eds C Poulsen Nautrup and R Tobias. Schluetersche Verlagsanstalt, Hannover 
Pourcelot L (1974) Applications cliniques de l'éxamen Doppler transcutane. In Velocimetrie ultrasonore Doppler pp 213-240 Ed. P Peronneau. INSERM, Paris

Schulman H (1987) The clinical implication of Doppler ultrasound analysis of the uterine and umbilical arteries American Journal of Obstetrics and Gynecology 156 889-893

Schulman H, Fleischer A, Farmakides G, Bracero L, Rochelson B and Grunefield L (1986) Development of uterine artery compliance in pregnancy as detected by Doppler ultrasound American Joumal of Obstetrics and Gynecology 155 1031-1036

Sonesson SE, Fouron JC, Teyssier G and Bonnin P (1994) Doppler echographic assessment of changes in the central circulation of the fetal sheep induced by maternal oxygen administration Acta Pediatrica 83 1007-1011
Stuart B, Drumm J, Fitzgerald DE and Duignan NM (1980) Fetal blood velocity waveforms in normal pregnancy British Journal of Obstetrics and Gynaecology 87 780-785

Thompson RS, Trudinger BJ and Cook CM (1988) Doppler ultrasound waveform indices: A:B ratio, pulsatility index and Pourcelot ratio British Journal of Obstetrics and Gynuecology 95 581-588

VanHuisseling H, Hasaart THM, Muijseres GJIM and Dehaan J (1991) Umbilical artery pulsatility index and placental vascular resistance during acute hypoxemia in fetal lambs Gynecologic and Obstetric Investigation 31 61-66

Yeager AE, Mohammed HO, Meyers-Wallen V, Van Nerson L and Concannon PW (1992) Ultrasonographic appearance of the uterus, placenta, fetus, fetal membranes throughout accurately timed pregnancy in beagles American Journal of Veterinary Research $31324-329$ 